\title{
DO USO CORPORATIVO AO USO SUBVERSIVO DO TERRITÓRIO NOS PAÍSES PERIFÉRICOS
}

\author{
the corporate use and the subversive use of territory in peripheral countries
}

\author{
Francisco das Chagas do Nascimento Júnior*
}

\begin{abstract}
Resumo
Este texto apresenta uma reunião de idéias e conceitos com o intuito de contribuir para uma interpretação crítica da formação territorial nos países periféricos. Como pressuposto teórico recorre-se a noção de território usado elaborada pelo geógrafo Milton Santos (1994). Para este eminente pensador brasileiro o território usado pode ser entendido como sinônimo de espaço banal, o espaço de todos os atores. Revisitando as distintas lógicas que regem a relação entre sociedade e território a partir das condições ideológicas imanentes ao processo de globalização, buscamos reconhecer os novos paradoxos e contradições que envolvem o uso do território. Por fim, afirma-se a unidade do movimento que antepõe a racionalidade hegemônica às contra-racionalidades praticadas pela população pobre dos países periféricos no atual período histórico.
\end{abstract}

Palavras-chaves: Países Periféricos; Uso do Território, Racionalidade Hegemônica, Contra-racionalidade.

\section{Abstract}

This paper does a combination of ideas with the objective of contribute to a critical interpretation of the territorial formation in peripheral countries. As theoretical based was employed the concept of used territory developed by the geographer Milton Santos (1994). For this Brazilian thinker the concept of used territory can be understood as synonymous of banal space, the space of all the actors. Revisiting the different logics that conduct the relation between society and territory from the ideological conditions inherent to the process of globalization, we seek to recognize the new paradoxes and contradictions that involve the use of territory as notion. Finally, it is asserted that the unity of the movement that oppose the hegemonic rationality is a rationality practiced by poor people of peripheral countries in the current historical period.

Key words: Peripheral Countries, Use of Territory, Hegemonic Racionality, Counter racionality.

\section{Resumen}

El presente artículo hace una reunión de ideas y conceptos con el fin de contribuir a una interpretación crítica de la formación territorial en los países periféricos. Como base teórica recurre a la noción del territorio usado desarrollado por el geógrafo Milton Santos (1994). Para este gran intelectual brasileño el território usado puede ser comprendido como sinónimo del espacio banal, el espacio de todos los actores sociales. Al examinar las diferentes lógicas que rigen la relación entre la sociedad y el territorio desde las condiciones ideológicas inherentes al proceso de globalización, buscamos reconocer las nuevas paradojas y contradicciones que definen el uso del territorio. Por último, se afirma la unidad del movimiento que crea una oposición entre la racionalidad hegemónica y la contra-racionalidad practicada por los pobres de los países periféricos en el período histórico actual.

Palabras-Claves: Países Periféricos, Uso del Territorio, Racionalidad Hegemónica, Contra-racionalidad.

(*) Doutorando da Pós-Graduação em Geografia - Universidade Estadual Paulista Júlio de Mesquita Filho/Rio Claro - Avenida 24, 1515, Bela Vista, Rio Claro (SP), Brasil, Tel: (+ 55 19) 35233707 - fnascimentojr@uol.com.br 


\section{INTRODUÇÃO}

Este texto não tem, de forma alguma, a pretensão de apresentar de maneira aprofundada e conclusiva uma teoria explicativa da formação do território nos países periféricos. Seu intento é, basicamente, o de reunir idéias e conceitos que de alguma forma venham auxiliar na elaboração de uma análise crítica e criteriosa das especificidades que envolvem aquelas formações sócioespaciais. Para tanto, fazemos uso de conceitos e noções, os quais servem de ponto de partida para, num momento subseqüente, refletirmos sobre os paradoxos que envolvem o uso do território nos países periféricos.

O território, em sua abordagem clássica, corresponde à extensão do espaço geográfico onde um Estado nacional exerce, com exclusividade, o domínio político-administrativo. Em outras palavras, o território se constituiria na base física e no fundamento existencial do Estado nacional (FIGHERA, 1994). Daí, desde sua origem as noções de Estado e de território serem consideradas como indissociáveis, o que levou ao fortalecimento da noção de Estado Territorial (SANTOS, 1994). No entanto, não podemos esquecer que o território se constitui também num amplo, diversificado e complexo quadro de vida ao qual ninguém escapa.

Embora recorrentemente a noção de território seja considerada um objeto de análise social tanto na ciência geográfica como nas demais ciências humanas, devemos destacar que em nosso entendimento não é o território em si que importa, mas o uso que dele se faz (SANTOS, 1994). O território é o lugar da existência coletiva, onde diferentes atores (econômicos, políticos, sociais) interagem cada qual a partir das lógicas próprias que regem o seu comportamento. Da mesma forma, o território como uma instância social historicamente constituída, conserva estruturas (físico-territoriais e socioculturais) as quais exercem papel ativo na determinação das ações e processos contemporâneos (SANTOS, 2002). Por isso, podemos falar que o que nos importa compreender é o território usado, sinônimo de espaço geográfico, sinônimo de espaço banal (SANTOS; SILVEIRA, 2001; SANTOS, 1994).

No mais, no atual período histórico, a noção clássica de Estado Territorial é constantemente açoitada pelas novas dinâmicas políticas e econômicas globais e pelos novos atores "transnacionais" (Empresas e instituições internacionais) que agem na remodelação dos territórios nacionais. Estabelece-se hoje uma relação dialética entre forças internas e forças externas na definição do uso do território nacional conforme se aprofunda o processo de globalização (SANTOS, 1985). São nestas circunstâncias que se consolida uma nova dinâmica no processo de formação do território nos países periféricos, ao passo que igualmente presencia-se a emergência de novas contradições e novos paradoxos no interior dessas formações sócioespaciais.

\section{ATORES E ESTRATÉGIAS TERRITORIAIS DE AÇÃO}

Para entendermos como o território é usado, isto é, como o espaço geográfico é apropriado e transformado pelo Estado, pelas empresas, pela sociedade civil, entre outros, é necessário também reconhecermos as diferenças no modo de ação dos atores sociais. Estes, ainda que coexistindo no território, não possuem a mesma forma e poder de atuação, nem as mesmas possibilidades de acesso aos recursos. Estado, empresas, instituições, sociedade civil, possuem diferentes escalas de ação, diferentes finalidades em suas estratégias de uso do território, diferentes capacidades de intervenção territorial.

Claude Raffestin (1980) distingue, grosso modo, os atores sociais em dois grupos: os atores paradigmáticos e os atores sintagmáticos. Para este autor os atores sintagmáticos (Estado, Empresa, Partidos Políticos, Igrejas, etc.) são aqueles que agem segundo um programa específico, buscando através da formulação de estratégias organizar o território conforme os projetos e finalidades políticas e econômicas que almejam. Já os atores paradigmáticos correspondem a um conjunto de indivíduos com características comuns (o povo, a nação). Contudo, apesar de se constituir como 
ator coletivo, um outro traço distintivo dos atores paradigmáticos é o fato de que estes não possuem um programa, uma ação pré-definida.

A partir da forma própria de ação dos atores sociais poderíamos identificar ao menos duas formas de relacionamento estabelecidas por esses com o território. Para uns, sobretudo os atores hegemônicos da economia, o território é visto apenas como recurso, ou seja, como meio que irá circunstancialmente potencializar suas estratégias de acumulação. Deste modo, especialmente as grandes corporações caracterizam-se por não manter compromisso estreito e duradouro com o lugar. As grandes empresas usam o território a seu talante, isto é, de acordo com os fatores conjunturais favoráveis à realização de determinado tipo de produção e/ou consumo em cada lugar.

Porém, para outros atores, para a população em geral, para o conjunto da sociedade nacional, o território é considerado um abrigo, ou seja, o lugar fundamental de sua existência. Nesta concepção a vigência de uma solidariedade orgânica (SANTOS, 2002) própria do lugar exacerba laços muito mais estreitos (e mesmo de dependência) entre alguns atores e o território. A partir deste tipo de relação temos, inclusive o desenvolvimento das relações de pertencimento e de identidade territorial sendo estabelecido entre a população e o lugar.

É possível, portanto, a partir dessas diferentes lógicas que imperam no uso do território, identificarmos desde já uma tensão e, muitas vezes, um conflito entre o que Milton Santos (1994; 2002) denomina verticalidades e horizontalidades na ordenação do espaço geográfico e na definição dos usos dos territórios.

As verticalidades são representadas por um conjunto de pontos distantes, ligados intencionalmente através de sistemas técnicos, científicos e informacionais. Estes lugares cumprem funções previamente estabelecidas, definidas a partir dos planos próprios de ação dos atores criadores das redes (especialmente as grandes empresas, com o apoio do Estado). Trata-se de uma solidariedade estritamente organizacional estabelecida entre lugares, que é imposta "de cima", verticalmente, conforme as estratégias dos atores hegemônicos da economia e da política (SANTOS, 1994; 2002). Por outro lado, as horizontalidades correspondem à contigüidade espacial, isto é, as relações de interdependência e complementaridade estabelecidas entre atores e entre lugares vizinhos (SANTOS, 1994). Dentro desta lógica os laços de solidariedade estabelecidos no lugar são criadores de uma coesão horizontal, ou seja, de uma união posta a serviço dos interesses da sociedade civil tomada como um todo (SANTOS, 2002). Trata-se, portanto, de uma dimensão territorial que revela uma lógica interna própria, dotada de um sentido próprio e localmente constituída (SANTOS, 2002).

Vale destacar que as verticalidades, como imposições estabelecidas "de fora" do lugar (tais como ordens, normas jurídicas, atividades econômicas) podem criar desarranjos locais, podem criar problemas à permanência dos laços locais/regionais de solidariedade estabelecidos no seio da sociedade. Daí notarmos, especialmente hoje (ou, sobretudo hoje), o papel importantíssimo exercido pelo Estado, visto como o ator que, em tese poderia equalizar as desigualdades sócioespaciais e suprimir as lógicas excludentes que desestruturam a organização social e fragmentam o território.

\section{ESPECIFICIDADES DA FORMAÇÃO DO TERRITÓRIO NA PERIFERIA}

Além de reconhecermos as diferenças na forma de ação dos atores sócioespaciais, para melhor compreendermos o uso do território nos países periféricos faz-se necessário reconhecermos as especificidades da formação do território nesses países. Sua situação de subdesenvolvimento e de dependência tanto política quanto econômica está diretamente associada ao papel histórico que estes ocuparam e ocupam na divisão internacional do trabalho.

Embora exista uma unidade no movimento total representado pela evolução do espaço mundial há que se reconhecer também, que junto a esta unidade caminha uma evolução diferencial das sociedades (SANTOS, 1977). Há uma seletividade e uma não uniformidade no aporte territorial das variáveis políticas, econômicas e tecnológicas que definem cada período histórico. Este, aliás, é o princípio fundador das diferenças existentes entre os lugares. 
Como nos lembra Santos (1978), atribuindo idéia fundadora a Max Sorre, uma das especificidades do espaço geográfico nos países subdesenvolvidos é que estes espaços se organizam e se reorganizam a partir de interesses distantes, de modo que "a cada necessidade imposta pelo sistema em vigor, a resposta foi [e é] encontrada nos países subdesenvolvidos, pela criação de uma nova região ou a transformação das regiões preexistentes [...]”. Deste modo, constituem-se então os espaços derivados, "[...] cujos princípios de organização devem-se muito mais a uma vontade longínqua do que aos impulsos ou organizações simplesmente locais" (SANTOS, 1978, p. 104-105). Assim é que as transformações técnico-territoriais nos países periféricos se dão com o objetivo de tornar o território economicamente mais eficiente, estreitamente alinhado aos imperativos e às lógicas que regulam a dinâmica da organização e da realização da produção em cada período.

Seguindo, de certa maneira, esta forma de pensamento, Isnard (1982) cria a noção de espaços extrovertidos, como forma de se referir àquelas regiões cuja configuração interna mostra uma clara orientação ao atendimento de demandas produtivas externas, o que revela uma subordinação destes espaços às ordens e desígnios estabelecidos pelo mercado internacional.

Nos países subdesenvolvidos o próprio processo de modernização territorial assume feições particulares, muito atreladas à estrutura de subordinação e dependência dessas formações sócioespaciais frente à ordenação do sistema econômico e político internacional (RIBEIRO, 2000; FURTADO, 1974). Conforme Darcy Ribeiro (2000), nos países da periferia do sistema capitalista o processo de modernização dar-se-ia de maneira reflexa, através de atualizações históricas, isto é promovendo inovações tecno-econômicas (às vezes com defasagens) exigidas para a incorporação parcial desses territórios aos modernos sistemas produtivos; enquanto, por outro lado, nos países cêntricos, o desenvolvimento econômico auto-centrado e a indução ao progresso tecnológico contínuo, possibilitariam que estes presenciassem uma aceleração evolutiva, permitindo aos mesmos comandar o processo geral de modernização e impor uma divisão internacional do trabalho a seu favor (RIBEIRO, 2000; SANTOS, 1985). Nos países periféricos, esse processo de modernização territorial vem, historicamente, privilegiando as atividades produtivas e os modernos circuitos de produção vinculados ao mercado internacional.

Jacques Lambert (1969) e Celso Furtado (1999) chamam ainda atenção para o caráter territorialmente seletivo e socialmente excludente dos processos de modernização que ocorrem especialmente no Brasil. Para estes autores tais modernizações se dão em função das demandas estabelecidas, sobretudo pela elite econômica urbana do país (incluindo a restrita classe média) e seus padrões de consumo. Assim, desde as instalações dos serviços básicos (como saúde e educação) até o incremento do parque industrial brasileiro, tais ondas de modernização seriam desfrutadas unicamente por uma pequena parcela da população, privilegiada em função do poder econômico e do acesso a administração que tal parcela privilegiada dispõe.

Considerada tal constituição do território nos países periféricos (internamente desigual e externamente subordinado) torna-se possível falarmos da consumação de uma verdadeira alienação territorial (CATAIA, 2003). Um território alienado é aquele cujo uso, isto é seu governo e seu destino, de uma forma ou de outra, parece fugir das "mãos" do seu povo, ou ainda escapam ao controle da maior parcela da sociedade. A nação não possui a capacidade de se auto-determinar. Tal situação se agrava no período atual à medida que, tendo o mundo como seu campo potencial de ação, empresas globais e instituições transnacionais (OMC, FMI, Banco Mundial, Bird) regulam "de fora" (remotamente) a vida política e econômica dos países e impõem, verticalmente, usos pré-determinados aos territórios nacionais, especialmente os territórios dos países periféricos.

\section{O MUNDO GLOBAL VISTO DA PERIFERIA: contos e fábulas}

Milton Santos, em seu livro "Por uma outra Globalização" (2001) alerta que para fugirmos das interpretações fáceis e enganosas do processo de globalização é necessário que compreendamos esse período a partir de três perspectivas: o mundo global como fábula; o mundo global como 
perversidade e, o mundo global como possibilidade. A compreensão do uso do território nos países periféricos exige que consideremos a existência conjunta e articulada destes "três mundos", num só mundo.

O período atual traz consigo um discurso e uma ideologia. O discurso hegemônico apregoa a globalização como algo inevitável e pinta sua caricatura através da construção de fábulas. Uma das mais representativas é a da existência de uma "aldeia global" e de uma integração total do planeta. Todavia, a integração dos países periféricos é parcial e espacialmente seletiva no interior daqueles territórios mais funcionais à economia internacional. Há, na verdade, espaços da globalização e não uma globalização absoluta do espaço como nos fazem crer.

A globalização apregoada como destino inevitável dos países após a ruína da velha ordem mundial apresenta-se, pelo discurso dominante, como caminho único ao desenvolvimento. Tal visão apresenta uma concepção de desenvolvimento econômico e social dada a partir de uma perspectiva linear, ou seja, como caminho natural dos países capitalistas. Tal leitura é fundada numa frágil inspiração apoiada na experiência dos países desenvolvidos. Entretanto, tal visão desconsidera o passado e as especificidades de formação dos países periféricos e, ao proceder desta maneira nega o caráter estrutural do subdesenvolvimento e da dependência política, econômica e tecnológica que estes presenciam. $\mathrm{O}$ espaço e as estruturas territoriais herdadas não teriam, da forma com que se apregoa, nenhum peso na definição dos rumos das nações. Neste sentido, em tal visão o subdesenvolvimento seria uma etapa na trajetória para se alcançar o desenvolvimento e, dada a atual convergência da história mundial, aqueles países ainda não plenamente desenvolvidos estariam "em vias de desenvolvimento".

Outro fundamento do discurso ideológico da globalização diz respeito à unificação do espaço advinda da disseminação planetária dos novos sistemas técnicos, científicos e informacionais. A difusão das redes e sua penetração pelos diversos territórios nacionais oferece as condições ideais para o surgimento de uma outra percepção enganosa da globalização - este processo estaria contribuído para um suposto "fim das fronteiras nacionais" e o "enfraquecimento dos Estados nacionais". No entanto, quando se leva em conta o território usado e a sociedade da forma como ela existe no território, esse mundo global que nos fazem crer só existe como fábula e só é vantajoso para aqueles atores privilegiados que podem ter o mundo como campo de ação. A porosidade das fronteiras é condição para que as grandes empresas transnacionais possam executar suas estratégias de acumulação estabelecidas em escala global. A organização em rede da produção e a articulação de distintos e distantes lugares em escala planetária para fins de realização do processo produtivo, impõe a supressão relativa dos obstáculos políticos (fronteiras e normas nacionais) entre os países, muitos dos quais (sobretudo os periféricos) passivamente participantes das estratégias de acumulação das empresas transnacionais. Trata-se, em outros termos, da incorporação de parcelas destes territórios as estratégias de acumulação das corporações globais e não de uma integração soberana dos países periféricos ao sistema econômico global.

Contudo, as fronteiras políticas são transpostas apenas pelo grande capital corporativo, tornando possível a produção da mais-valia global. O espaço só se torna fluido para a mobilidade dos atores hegemônicos da economia e da política, enquanto para os demais a viscosidade territorial ainda impera. Exemplo maior disso é a migração das populações oriundas dos países pobres rumo aos países ricos, mobilidade esta que se apresenta extremamente controlada e combatida pelos países do centro. Se para as grandes corporações (oriundas majoritariamente dos países ricos) o mundo global se apresenta como um campo de oportunidades para seus negócios, para as populações pobres, a mobilidade é restrita e as fronteiras se mantêm bastante sólidas e pouco porosas.

\section{O MUNDO GLOBAL VISTO DA PERIFERIA: realidade e perversidade}

A emergência da nova ordem mundial e a unificação do sistema econômico internacional caminha sob a orientação de um pensamento único, o qual vem impor as condições necessárias para 
que, sobretudo os países periféricos alcancem o tão almejado "desenvolvimento" no período atual. O neoliberalismo apresenta-se como o fundamento teórico e ideológico que, desde os anos 1980, rege o movimento de convergência das formas de regulação dos territórios - algo essencial para que, de fato, o mundo se torne o campo de ação dos atores hegemônicos da economia e da política.

A economia política espacial que resulta deste discurso ideológico propõe novas formas de regulação da vida nos territórios, norteadas mais pelas lógicas de mercado do que pela intervenção do aparelho de Estado. Neste sentido tratar-se-ia de uma tentativa de "desestatização" do território e uma progressiva liberalização/mercantilização de sua dinâmica de organização e funcionamento.

Evidência disso é o papel desempenhado por organismos transnacionais como o FMI, o Banco Mundial, o Bird e todos os grandes meios de informação que lhes servem, atuando como propagadores desse pensamento e, em muitas situações, impondo políticas econômicas que tratam de "preparar" os territórios nacionais para a sua integração ao atual sistema econômico global. O chamado "receituário neoliberal" se caracteriza na expressão máxima dessa nova forma de regulação dos territórios, que responde diretamente aos princípios fundadores da ordem econômica hegemônica.

Na América Latina, sobretudo a partir dos anos 1990, observa-se um esforço conduzido por alguns organismos e partidos políticos para a instituição de um "Estado Mínimo" e ainda uma maior abertura econômica destes países ao capital estrangeiro. Novas formas de coerção e ingerências dos territórios nacionais nos países subdesenvolvidos são produzidas, situação essa que se encontra legitimada pelas ações do Estado. Programas de privatização de empresas públicas são estabelecidos, novas regras de concessão de serviços estatais à iniciativa privada são regulamentadas e, políticas públicas orientadas a servir determinados circuitos produtivos, aqueles mais funcionais ao mercado mundial, vão definir um uso neoliberal do território viabilizado e legitimado pelo próprio Estado.

No entanto, o mundo global visto a partir da periferia constitui-se numa verdadeira "fábrica de perversidades" (SANTOS, 2001). A regulação mercantil da vida da população nos países pobres tende a gerar amplas e profundas desigualdades sociais e territoriais, caracterizando-se como situação favorável apenas para as grandes corporações e desfavorável para a maior parte da população, segregada em função da lógica mercantil, ou ainda da democracia de mercado instituída em países onde a maioria da população se encontra em situação de pobreza.

O aprofundamento das políticas neoliberais nos países periféricos confere maior viabilidade para as estratégias de acumulação de empresas transnacionais que, estimuladas por incentivos fiscais e territoriais múltiplos, ampliam expressivamente os seus lucros nestes países. O território e os recursos de que dispõe são utilizados por tais atores que, de modo corporativo, orientam os investimentos públicos em infra-estruturas (sobretudo as de transporte e informação), potencializando assim suas estratégias territoriais de acumulação. O próprio Estado atua como cooperador para que as modernizações sejam seletivas e o território seja apropriado de forma corporativa, isto é, apenas por alguns. Assim, a idéia de "ausência do Estado" ou de "Estado mínimo" torna-se uma falácia, já que tal instituição se faz presente e é fundamental à viabilização do território como recurso aos atores hegemônicos.

A atual racionalidade hegemônica estimula e defende a competitividade econômica. Esta se torna um imperativo na remodelação dos territórios face à busca pelo aumento das trocas comerciais e dos fluxos financeiros, algo próprio do atual estágio de expansão e aprofundamento do sistema capitalista. Parcelas dos territórios periféricos são convocadas a participar do atual sistema econômico de forma eficiente, competitiva, respondendo precisamente as exigências quantitativas e qualitativas impostas pelo mercado. A expressão geográfica desse comportamento corresponde, não obstante, às modernizações do território e da produção. A ilusão do "tornar-se competitivo" possível de ser observada através da tecnicização e da automação da produção nos lugares traz, como conseqüências, o reforço do desemprego estrutural e a ampliação da segregação sócioespacial. Trata-se de um efeito direto da modernização territorial arquitetada de modo vertical (imposta "de cima"), voltada a gerar benefícios exclusivamente econômicos. 
Quando o território é produzido e organizado para o uso seleto dos atores hegemônicos, em detrimento da maioria da população, pode-se dizer que o uso do território torna-se corporativo. Nestes termos, podemos pensar que, se o receituário neoliberal proporciona de um lado a integração dos territórios nacionais à economia internacional, associado a esse movimento tal processo também produz a desagregação/fragmentação dos territórios nos países pobres da periferia do capitalismo. Neste mesmo sentido poderíamos falar que a dependência e a subordinação dos países da periferia, embora sob novas feições, se intensificam na globalização, fazendo com que os pobres, visando a sua própria sobrevivência, reinventem, ao seu modo, práticas e usos territoriais.

\section{O MUNDO E A GLOBALIZAÇÃO (RE)INVENTADOS “DE BAIXO”}

O mundo global que nos fazem crer e que institui, via racionalidade hegemônica, um verdadeiro globalitarismo (SANTOS, 2001) aos países periféricos, também sofre reveses nos lugares. É no território usado, espaço de todos, que tal mundo de fábulas, apregoado pela globalização corporativa, é dialeticamente negado. A situação de escassez enfrentada pela população mais pobre é criadora constante de alternativas (de trabalho e de renda) que de um modo ou de outro garantem a sobrevivência no lugar. Esta busca pelas condições básicas de sobrevivência evidencia a presença de outras lógicas de uso do território.

Se a atual economia política praticada nos países periféricos evidencia a natureza corporativa da racionalidade hegemônica no território, muitas atividades praticadas pelos "de baixo" (os mais pobres, as vítimas do desemprego estrutural, os excluídos das benesses da globalização), dotadas de significativa expressão econômica, apresentam uma contra-racionalidade e até mesmo uma revanche dos pobres a tal ordenação perversa do período. A baixa qualificação profissional, a escassez de emprego, a dificuldade de acesso aos serviços básicos exigem da população pobre maior flexibilidade de adaptação às possibilidades de renda e trabalho nos países periféricos.

Como num movimento articulado ao de segregação produzido pelo processo de modernização do território observa-se "aflorar", sobretudo nos grandes centros urbanos dos países periféricos, um circuito inferior da economia urbana (SANTOS, 2004) que se expande de acordo com as crises econômicas, o aprofundamento do desemprego estrutural e a capacidade da população pobre de inventar alternativas factuais para sua sobrevivência. A flexibilidade tropical (SANTOS, 1998), esse atributo próprio dos países pobres, representa, em certa medida, a resposta dada pelos "de baixo" à organização corporativa do território, defendendo outras possibilidades de uso que encontram no território um verdadeiro abrigo (SANTOS, 2001). Os pobres, isto é, aqueles homens que enfrentam os antagonismos do desenvolvimento do capitalismo na periferia são, a todo o momento, obrigados a reinventar suas condições materiais de vida no território usado, já que cotidianamente se defrontam com a escassez.

Segundo Santos (2004), o circuito inferior da economia urbana é caracterizado pelas atividades realizadas com baixo grau de tecnologia, apresentam ainda uma baixa produtividade, mas por outro lado possuem a capacidade de absorver grande quantidade de força de trabalho. Em alguns casos, compõem esse mesmo circuito inferior atividades tradicionalmente definidas como "informais" ou "irregulares", visto que muitas delas não obedecem e mesmo subvertem normas e regras estabelecidas pelo Estado. Aliás, é esse amplo e diversificado quadro de atividades e situações que tornam o circuito inferior da economia urbana além de perene e flexível, extremamente dinâmico e, aparentemente, contraditório nos países periféricos.

A dinamicidade do circuito inferior da economia advém da capacidade que este possui em diversificar suas atividades e mover-se pelos centros urbanos buscando, à sua maneira, alcançar e atender as demandas do seu amplo mercado consumidor (a população de baixa renda). Presente principalmente em áreas desvalorizadas (mas muito freqüentadas) das cidades, tais atividades econômicas realizadas pelos "de baixo" (comércios e serviços pouco capitalizados e de pequeno 
porte, vendedores ambulantes, etc.) se fazem presentes e mesmo concorrem com as atividades capitalizadas do circuito superior da economia urbana (SANTOS, 2004).

Ao passo em que a modernização da produção e do território, em marcha acelerada nas últimas décadas, produz uma nova estrutura do emprego, gerando consigo novas exigências para a ocupação de postos de trabalho e um desemprego tornado estrutural, o circuito inferior da economia urbana se torna permanente e amplia sua representatividade. Torna-se, portanto, uma alternativa (recorrente) para o enfrentamento da crise social nos países periféricos, pois possibilita a geração de renda justamente entre os mais pobres.

\section{O USO SUBVERSIVO DO TERRITÓRIO}

Por subverter normas e regulamentações impostas "de cima", as atividades do circuito inferior da economia urbana são enquadradas, algumas vezes, numa situação oficial de ilegalidade ou informalidade. Estes são os casos de atividades consideradas ilegais muito associadas ao circuito inferior - a reprodução ilegal de mercadorias ("pirataria"), o contrabando de mercadorias, os transportes não autorizados (as "lotações"), etc. (MACHADO, 2000; TOZI, 2008; PEREIRA, 2009). Trata-se, em todas as situações, de uma subversão das regras formalmente constituídas, ato que, no limite, tem como conseqüência a criminalização de seus praticantes. Tais normas e legislações ("regras formais de comportamento") por representarem uma única racionalidade, no mais das vezes desconsideram os obstáculos impostos à existência de importante parcela da sociedade e, por isso, nunca acolhem os interesses (e as necessidades) que motivam as práticas e a permanência deste uso subversivo do território.

Mas, embora a interpretação imediata dessas distintas lógicas de uso do território possa, à primeira vista, dar a impressão de um sistema dualista (uma economia moderna e capitalizada versus uma economia pobre e pouco organizada), é importante destacar também os aspectos de articulação e até de complementaridade estabelecido entre os circuitos superior e inferior da economia urbana. Hoje, dada a tamanha importância e representatividade do circuito inferior da economia, com freqüência os atores hegemônicos integram ao seu circuito de produção/distribuição algumas das atividades produtivas desenvolvidas pelos "de baixo". Exemplo disso é a estratégia das grandes corporações financeiras que estendem as possibilidades de compra eletrônica, via cartão de crédito, aos mercados populares, ou ainda, aqueles casos de grandes redes de varejo, tornadas alvo de indiciamentos policias, devido às relações comerciais ilegais que o circuito superior mantêm com fornecedores de produtos contrabandeados ou pirateados. Assim, nos países periféricos, os dois circuitos da economia urbana mantêm profundas e estreitas relações.

\section{CONSIDERAÇÕES FINAIS}

Espaço de todos os atores, o território usado escancara os paradoxos e as contradições que envolvem a formação do território nos países periféricos, no período atual. $\mathrm{O}$ uso subversivo do território constitui um contraponto dos pobres à ordenação imposta pelos Estados-potências, pelas instituições internacionais e pelas empresas globais que usam os territórios nacionais dos países periféricos a seu talante - a despeito dos interesses e das necessidades imediatas das populações locais. Em outros termos, afirma-se a unidade do movimento que antepõe a racionalidade hegemônica às contra-racionalidades praticadas pela população pobre dos países periféricos no atual período histórico.

A flexibilidade tropical (SANTOS, 1998), vista a partir da adaptação dos pobres à situação de escassez, às ausências e restrições de diversas naturezas que são impostas à sua existência (acesso à renda, trabalho, serviços básicos, etc.) se apresenta como uma revanche do território à racionalidade hegemônica, isto é, se constitui ao mesmo tempo numa contra-racionalidade e exacerba 
outras razões de uso do território, mais solidárias, criativas, humanitárias e que revelam o sentido profundo do território: ser o abrigo da nação.

Enquanto não se funda o mercado socialmente necessário (RIBEIRO, 2005) - ou seja, um mercado que sirva ao conjunto da sociedade, à massa de pobres e desempregados que se amplia e se perpetua nos países periféricos, o uso subversivo do território será responsável por evidenciar a clara tensão/crise social estabelecida pela forma egoística que formaliza o uso corporativo destes territórios. Nestas circunstâncias surge a questão terminante... afinal, de quem é o território?

\section{AGRADECIMENTO}

As críticas e sugestões realizadas por Mirlei Fachini Vicente Pereira, que muito ajudaram à finalização do texto.

\section{REFERÊNCIA BIBLIOGRÁFICA}

CATAIA, M. A Alienação do território - O papel da guerra fiscal no uso, organização e regulação do território Brasileiro In: SOUZA, M. A. A. (Org.). Território Brasileiro: usos e abusos. Campinas: Territorial, 2003. p.397-407.

FIGHERA, D. Estado e território: Suas relações e o território nacional. In: SANTOS, M; SOUZA, M. A.; SILVEIRA, M. L. (Org.) Território: Globalização e Fragmentação. $5^{\circ}$ ed., São Paulo: Hucitec/Anpur, 1994, p. $108-115$.

FURTADO, C. O Mito do desenvolvimento econômico. São Paulo: Círculo do Livro, 1974.

FURTADO, C. O Longo Amanhecer: reflexões sobre a formação do Brasil. Rio de Janeiro: Paz e Terra, 1999. ISNARD, H. O Espaço geográfico. Coimbra: Almedina, 1982.

LAMBERT, J. Os Dois Brasis. São Paulo: Ed. Nacional. 1969.

MACHADO, L. O. Limites e fronteiras. Da alta diplomacia aos circuitos da ilegalidade. Revista Território, Rio de Janeiro, v. 8, p. 9-29, 2000.

PEREIRA, M. F. V. Redes, sistemas de transportes e as novas dinâmicas do território no período atual: notas sobre o caso brasileiro. Sociedade \& Natureza, Uberlândia, 21 (1): 121-129, ABR. 2009.

RAFESTTIN, C. Por uma geografia do Poder. São Paulo: Ática, 1993.

RIBEIRO, D. O Processo civilizatório: estudos da antropologia da civilização: etapas da evolução sociocultural. São Paulo: Companhia das Letras; Publifolha, 2000.

RIBEIRO, A. C. T. Pequena reflexão sobre categorias da teoria crítica do espaço: território usado, território praticado. In: SOUZA, Maria Adélia Aparecida de (Org.). Território Brasileiro: usos e abusos. Campinas, Territorial, 2003. p. 29-40.

RIBEIRO, A. C. T. Território usado e humanismo concreto: o mercado socialmente necessário. In: SILVA, C. A.; BERNARDES, J. A.; ARRUZZO, R. C.; RIBEIRO, A. C. T. Formas em Crise: Utopias Necessárias. Rio de Janeiro: Arquimedes, 2005.

SANTOS, M. Sociedade e Espaço: A formação social como teoria e como método. Boletim Paulista de Geografia, São Paulo, n.4, p. 81-99, jun. 1977.

SANTOS, M. O Trabalho do Geógrafo no Terceiro Mundo. São Paulo; Hucitec, 1978.

SANTOS, M. Espaço e método. São Paulo: Nobel, 1985.

SANTOS, M. Metamorfoses do espaço habitado: Fundamentos Teóricos e Metodológicos da Geografia. São Paulo: Ed. Hucitec, 1988.

SANTOS, M. O retorno do território. In: SANTOS, M; ADÉLIA, M; LAURA, M (Org.) Território: Globalização e Fragmentação. São Paulo: Hucitec/Anpur, 1994. p.15-20.

SANTOS, M. Técnica, Espaço, Tempo: Globalização e Meio técnico-científico informacional. São Paulo: Hucitec, 1998. 
NASCIMENTO JÚNIOR, F. C.

SANTOS, M. Por uma outra Globalização: do pensamento único à consciência universal. Rio de Janeiro: Record, 2001.

SANTOS, M. A Natureza do espaço: técnica e tempo, razão e emoção. São Paulo: Edusp, 2002.

SANTOS, M. O Espaço dividido: Os dois circuitos da economia urbana dos Países Subdesenvolvidos. São Paulo: Editora USP, 2004.

SANTOS, M.; SILVEIRA, M. L. O Brasil: território e sociedade no início do século XXI. $2^{\circ}$ edição, Rio de Janeiro: Record, 2001.

TOZI, F. Da pirataria à flexibilidade tropical: uma reflexão sobre a filosofia das técnicas. In: XV Encontro Nacional de Geógrafos, 2008, São Paulo. Anais do XV Encontro Nacional de Geógrafos, 2008.

Trabalho enviado em junho de 2011

Trabalho aceito em julho de 2011 